\title{
Elaboração e implementação de currículos críticos/transformadores: um olhar para um processo formativo no âmbito do PIBID
}

\begin{abstract}
RESUMO
Este estudo apresenta os resultados obtidos a partir de um processo formativo desenvolvido com bolsistas e supervisores do Programa Institucional de Bolsa de Iniciação à Docência (PIBID) no intuito de refletir sobre a possibilidade de implementação de currículos críticos/transformadores no ensino de ciências. Os resultados obtidos a partir de questionário, entrevistas e diários elaborados pelos sujeitos participantes da pesquisa foram analisados a luz da Analise Textual Discursiva (ATD) e chegou-se a quatro categorias emergentes: A reestruturação do currículo a partir do trabalho com os Temas Geradores; O trabalho interdisciplinar e coletivo; O diálogo como forma de possibilitar a problematização da realidade; e Um novo olhar para a escola e para a instituição de Ensino Superior. A partir das categorias foi possível reconhecer a importância da formação inicial e continuada na elaboração de currículos críticos, bem como a necessidade de um trabalho coletivo e interdisciplinar no ensino de ciências.
\end{abstract}

PALAVRAS-CHAVE: Currículo. Temas Geradores. PIBID. 


\section{INTRODUÇÃO}

Ainda hoje é possível observar um ensino de ciências baseado apenas em transmissões de informações, sem possibilitar aos alunos oportunidade para a discussão, reflexão e contextualização do que é trabalhado em aula com a realidade vivenciada (PANIZ, 2017). O currículo ainda é visto, na maioria das vezes, de forma disciplinar e fragmentada, sendo o objetivo da escola apenas transmitir conceitos que devem ser memorizados pelos alunos. Essa ideia de currículo vem sendo discutida criticamente por diversos autores (HALMENSCHLAGER, 2014; DELIZOICOV; ANGOTTI; PERNAMBUCO, 2011; MOREIRA, 2010; MUENCHEN, 2010 AULER, 2007) e é discutida no presente trabalho.

Defende-se um currículo de ciências não mais pautado em disciplinas fragmentadas, mas, sim, que considere o diálogo como forma de problematizar a realidade vivenciada pelos sujeitos que fazem parte do processo educativo, visando à construção de conhecimentos contextualizados que possam possibilitar a mudança dessa realidade. Para isso, necessita-se repensar a escola, ou seja, é preciso vê-la como instituição de construção de conhecimentos, de diálogo entre diversas culturas e de acolhimento das diferenças presentes nela.

Dessa forma, o presente artigo apresenta resultados obtidos a partir de uma proposta de intervenção curricular em escolas de Educação Básica parceiras do Programa Institucional de Bolsa de Iniciação à Docência (PIBID). O PIBID é um programa de iniciação à docência que prevê a inserção de alunos das licenciaturas no cotidiano das escolas da rede pública, planejando e participando de experiências metodológicas, tecnológicas e práticas docentes de caráter inovador e interdisciplinar, e que buscam a superação de problemas identificados no processo de ensino-aprendizagem.

\section{REFERENCIAL TEÓRICO}

De acordo com Sacristán (2013), o currículo é cultura, ele é uma das culturas possíveis. Nesse sentido, o autor questiona quais conteúdos têm a cultura que se considera adequada. Essa discussão é pertinente, uma vez que se vive numa sociedade plural em relação a ideias, a culturas, a pensamentos, enfim, uma sociedade democrática onde esse pluralismo e os conflitos inevitáveis devem ser abordados explicitamente. Para Sacristán, "É necessário que se tornem públicas as diferenças e que estejamos abertos ao diálogo e à participação de todos os agentes e posições controversas" (2013, p. 11).

Nesse sentido, a escola precisa repensar seu papel, não se restringindo à transmissão de conhecimentos, mas sendo um espaço de discussão de ideias, de troca de conhecimentos de experiências e de convívio produtivo. Isso porque a escola não é um conjunto de aulas, é muito mais que isso, deve ser um projeto da comunidade compartilhado, que se desenvolve em um contexto, por meio da ação conjunta de todos os sujeitos envolvidos.

Segundo Auler (2007), nos últimos anos, têm-se apresentado algumas propostas de intervenção curricular buscando a superação de problemas e limitações no ensino, que são apontadas na literatura das pesquisas em Ensino de Ciências como as chamadas Abordagens Temáticas. $O$ aspecto mais significativo da proposta do trabalho com temas é a proposição em relação ao currículo escolar 
(MUENCHEN, 2010; ARAÚJO, 2015). Nessa perspectiva, a estruturação das atividades e sua implementação rompem com a lógica disciplinar, ou seja, o currículo não é mais visto numa abordagem conceitual. A abordagem conceitual, de acordo com Delizoicov, Angotti e Pernambuco (2007), é a perspectiva cuja lógica de organização é estruturada nos conceitos científicos, os quais são a base para a seleção dos conteúdos de ensino. Já a abordagem temática,

[...] é uma perspectiva na qual a lógica de organização é estruturada com base em temas, com os quais são selecionados os conteúdos de ensino das. Nessa abordagem, a conceituação científica da programação é subordinada ao tema (DELIZOICOV, 2007, p.189).

No presente trabalho, o foco é a Abordagem Temática Freireana (ATF) que é uma das modalidades de Abordagem Temática. A Abordagem Temática Freireana (FREIRE, 2014; DELIZOICOV, 1991) propõe que, a partir da realidade do aluno e do diálogo, sejam pensados os conhecimentos necessários e selecionados para a compreensão de um tema, chamado de Tema Gerador. O Tema Gerador é uma situação problema vivenciada pela comunidade e que pode ainda não ser percebida por ela.

Mesmo não sendo um teórico de currículo, Freire (2014), em sua obra Pedagogia do Oprimido, apresenta reflexões importantes sobre o currículo, pois critica uma educação bancária que visualiza os alunos como receptores de conhecimentos.

De acordo com Muenchen, 2010

A transposição da perspectiva de Freire propõe uma nova relação entre currículo e comunidade escolar. Sua análise leva em consideração, na programação e no planejamento didático-pedagógico, uma configuração curricular baseada em temas, os quais são os objetos de estudo a serem compreendidos no processo educacional (MUENCHEN, 2010, p. 10).

Nesse sentido, o autor apresenta um currículo no qual é considerada a realidade vivenciada pelos educandos. Partindo dessa realidade, surgem os temas que vão constituir o conteúdo programático.

Assim, os Temas Geradores só são geradores de ação-reflexão-ação se carregados de conteúdos sociais e políticos com significados concretos para a vida dos educandos (REIS, 2016). Para chegar aos Temas Geradores, na presente pesquisa, foi utilizado os Três Momentos Pedagógicos (3MP) como estruturantes de currículo.

De acordo com Ferreira, Paniz e Muenchen (2016), diversos trabalhos da área de ensino de ciências sinalizam a discussão acerca dos chamados 3MP, seja utilizando-os como ferramenta metodológica (SANTOS, et al., 2011; DEMARTINI e SILVA, 2013), seja como estruturantes de currículos (ARAÚJO, 2015; CENTA, 2015).

Como estruturantes de currículos, os 3MP são definidos como: Estudo da Realidade (ER), Organização do Conhecimento (OC) e Aplicação do Conhecimento (AC). No ER, se investiga a realidade na qual a comunidade está inserida a partir de questionários, entrevistas, visitas em instituições, dentre outros. Na OC, são utilizados os dados obtidos no ER para, a partir disso, serem definidos os conhecimentos que precisam ser trabalhados para a compreensão do tema. Por fim, a (AC) destina-se às implementações em sala de aula, bem como à avaliação 
de todo processo, no intuito de reconhecer mudanças em relação a compreensão sobre o tema.

\title{
METODOLOGIA
}

Para realização da pesquisa foi organizado e implementado um processo formativo com atividades semanais, totalizando 80 horas, para 30 participantes. Desses 30 participantes, 26 sujeitos eram bolsistas do PIBID, ou seja, alunos que estavam em formação inicial. Os outros 4 sujeitos participantes eram docentes de quatro escolas de Educação Básica e bolsistas supervisores do PIBID. O processo formativo foi organizado com uma parte teórica, na qual foram discutidas questões relacionadas ao currículo, à interdisciplinaridade, à abordagem temática e aos momentos pedagógicos como estruturantes de currículos, assim como uma parte prática, com a realização de pesquisa nas comunidades para identificação dos Temas Geradores e posterior planejamento e implementação dos temas em sala de aula. Para realização da identificação dos temas geradores, os sujeitos participantes, foram organizados de acordo com o número de escolas abrangidas pelo PIBID, ou seja, quatro grupos. Cada grupo organizou e realizou o Estudo da Realidade, a partir de questionários e entrevistas com a comunidade (pais, alunos, professores, comerciantes, dentre outros) bem como estudos de documentos e jornais da cidade para auxiliar na escolha do tema gerador. Após a escolha dos temas, os grupos elaboraram os planejamentos e posteriormente implementaram em sala de aula.

Durante o desenvolvimento do processo formativo, foram registradas, pela pesquisadora e pelos participantes, num diário, as impressões e as reflexões, os questionamentos, as discussões, as atividades como resenhas e as problematizações realizadas no decorrer da pesquisa. Ao final do curso, foi realizada entrevista semiestruturada com bolsistas e com os professores supervisores seguindo os princípios éticos da pesquisa.

A partir dos dados coletados nos questionários, nas entrevistas e nos diários dos sujeitos participantes (bolsistas do PIBID) e da pesquisadora, além dos planejamentos elaborados pelos grupos, as análises foram realizadas com base na Análise Textual Discursiva (ATD).

Segundo Moraes, a ATD caracteriza-se como,

\begin{abstract}
Um processo auto organizado de construção de compreensão em que novos entendimentos emergem de uma sequência recursiva de três componentes: a unitarização - desconstrução dos textos do corpus; a categorização estabelecimento de relações entre os elementos unitários; e por último o captar de um novo emergente em que a nova compreensão é comunicada e validada (MORAES, 2003, p. 192).
\end{abstract}

A unitarização consiste num processo de desmontagem dos textos e implica em colocar foco nos detalhes e nas partes que os compõem. Pretende-se perceber os sentidos dos textos. Da desconstrução dos textos surgem as unidades de análise, também denominadas de unidades de significado ou de sentido (MORAES, 2003).

As unidades de significado podem ser organizadas a partir de categorias (categorização), que podem ser a priori, onde o pesquisador já possui antes as 
categorias que vai utilizar ou emergentes, ou seja, que aparecem a partir da desconstrução do texto, que é o caso da presente pesquisa.

\title{
RESULTADOS E DISCUSSÃO
}

Através das análises dos questionários, entrevistas e diários dos sujeitos participantes do processo formativo chegou-se a quatro categorias emergentes, ou seja, construídas a partir dos dados, sendo elas: A reestruturação do currículo a partir do trabalho com os Temas Geradores; O trabalho interdisciplinar e coletivo; O diálogo como forma de possibilitar a problematização da realidade; e Um novo olhar para a escola e para a instituição de Ensino Superior. A seguir, apresentamos as categorias individualmente.

\section{CATEGORIA 1: A REESTRUTURAÇÃO DO CURRÍCULO A PARTIR DO TRABALHO COM OS TEMAS GERADORES}

Nesta categoria, apresentamos como o trabalho a partir de temas geradores possibilitou aos sujeitos participantes da pesquisa, refletirem sobre como é possível pensar o currículo de ciências de maneira conjunta e integrada, apesar das dificuldades em trabalhar nessa perspectiva.

De acordo com a escrita de um supervisor, a implementação dos temas geradores apresentou potencialidades, além da satisfação e alegria de ter participado e vivenciado o processo.

\begin{abstract}
Foi diferente este trabalho, a comunidade participou e a gente trabalhou junto com a biologia, junto com a minha colega de escola (minha colega faz tempo) e que nunca tínhamos conseguido fazer nada juntos, assim, tão efetivo, pois cada um vem na escola em alguns dias (DIÁRIO SUPERVISOR B).
\end{abstract}

Os resultados do trabalho motivaram o professor e isso pode contribuir com a busca de novas propostas e implementações de práticas educativas que visem uma reorientação curricular. No entanto, como afirmam Tomazetti e Benetti,

É uma tarefa bastante difícil, considerados os moldes ainda tradicionais da formação dos professores, nos quais o conteúdo é aquilo que é apresentado pelo professor de uma forma monológica e não desafiadora, como aquilo que já foi pensado. O "conteúdo" é apresentado como um bloco estático de saber e não como uma matéria viva que vai tomando forma no tempo da aula. A tarefa do professor não é apenas "transmiti-lo", "apresentá-lo" aos alunos, mas acompanhado deles construir o movimento de sua produção, de sua reformulação (grifo meu) (TOMAZETTI; BENETTI, 2012, p. 1034).

Para isso, os professores que estão atuando na escola e os futuros docentes que estão em formação inicial necessitam ter ciência de seu importante papel na elaboração de um currículo que busque a formação de sujeitos capazes de compreender os acontecimentos ao seu redor, bem como opinar e modificar a realidade.

Já em 1992, Krasilchik apontava para a necessidade de repensar os currículos escolares, bem como para a necessidade de participação de todos nas discussões e na elaboração destes. 
Uma profunda revisão dos currículos escolares mostra-se um passo urgente e inadiável para que se chegue a recomendações que orientem a todos os envolvidos no processo, desde a elaboração de programas das disciplinas científicas até as salas de aula, onde os alunos participem das atividades que Ihes permitam adquirir conhecimentos e ver a ciência não só como processo de busca desses conhecimentos, mas como instituição social que influi poderosamente em suas vidas (KRASILCHIK, 1992, p. 07).

Uma concepção que os sujeitos apresentavam ao iniciar o processo formativo apresentado na presente pesquisa, era a ideia de que os conteúdos devem ser trabalhados de forma linear. No entanto, a implementação dos temas geradores, ampliou a visão dos sujeitos.

\begin{abstract}
Na minha área tem que ensinar primeiro a estrutura atômica, para depois a tabela periódica, para depois as ligações, para depois começar com química orgânica, pode ligar química orgânica, que é o que tem elemento químico junto com as ligações, junto com a tabela periódica. [..] com esse trabalho não foi assim, não ficou aquela coisa fechada que precisa ser seguida. Bom, agora vamos ler, vamos aprender a estrutura de Bohr, depois de Rutherford e assim por diante (BOLSISTA A).
\end{abstract}

Eu acho que a escola, pelo menos não permite muito sabe, não dá muita liberdade de trabalhar. Tu tens que seguir aquela sequência que eles querem, tem que seguir aquela rotina, o currículo estabelecido, a sequência e a ordem dos conteúdos. Primeiro isso, depois aquilo. Nós conseguimos fazer e mostrar que não precisa seguir a ordem e os alunos entenderam (BOLSISTA C).

Auler (2007) afirma que

Foi internalizado, naturalizado, que o currículo repetido ano após ano, é o ideal. Nesta concepção, absolutamente hegemônica, o professor foi posto, hierarquicamente, numa posição inferior, seu papel for reduzido a busca incessante de novas metodologias, novas técnicas para melhor cumprir programas para "vencer conteúdos" (AULER, 2007, p. 174).

Durante os planejamentos em grupos, realizados para sistematizar os conhecimentos necessários para compreensão do tema, os sujeitos participantes tiveram inicialmente a preocupação com a ordem e com a sequência a ser seguida, como é possível reconhecer a partir do trecho do diário da supervisora: "Estou preocupada com a sequência dos conteúdos. Com esse tema, tem coisas do terceiro ano e eles estão no segundo" (SUPERVISORA E) e a partir de falas durante o processo formativo já descrito anteriormente, registradas no diário da pesquisadora.

Alguns bolsistas e supervisoras estão preocupados com a sequência dos conteúdos e me parece que não estão acreditando que pode dar certo o trabalho. Eles acham que se não seguir a sequência os alunos não vão entender (DIÁRIO DA PESQUISADORA).

Os bolsistas também destacaram a possibilidade de trabalhar sem a sequência definida anteriormente: "Nós abordamos conteúdos de terceiro ano, do primeiro ano, conteúdo do segundo, e tem uma ligação a entender, assim não tem uma dificuldade" (BOLSISTA A); "Com o Tema Gerador, não nos preocupamos se o conteúdo era ou não do ano, a gente trabalhou e, como foi a partir do tema e da realidade, acredito que eles entenderam sim" (BOLSISTA F). 
Quando questionados em relação ao trabalho com Temas Geradores, os bolsistas explicitaram que é uma possibilidade, mas também destacaram a "obrigatoriedade" de seguir a lista de conteúdos e a forma tradicionalmente trabalhada.

\begin{abstract}
Se o currículo fosse assim seria bom, mas terá que ter uma mudança de visão. É bem difícil sair da lógica dos conteúdos que estão no livro. Não precisa pensar, só fazer. Só que essa coisa de só dar conteúdos, sem relacionar e ter significado para os alunos, não está mais dando certo professora. Eu vejo no estágio também (BOLSISTA J).
\end{abstract}

Só a metodologia não vai adiantar, eu acredito que virou rotina o currículo. Os alunos sabem o que vão estudar em todos os anos, já tem uma lista. Estão alienados e uma mudança no currículo poderia ajudar (BOLSISTA I).

A partir das falas dos bolsistas, pode-se perceber as dificuldades e resistências de compreensão que existem em relação à reestruturação curricular a partir dos Temas Geradores. Todavia, estes bolsistas apresentam uma postura crítica, quando destacam que a escola precisa modificar a visão em relação ao currículo. Essa mudança pode ser reconhecida, principalmente em relação ao bolsista J que, no questionário inicial, apresentou uma concepção diferente. Para ele "Os alunos cansam das aulas. É preciso mudar as metodologias toda hora, para ver se eles aprendem. Eles não têm mais vontade de aprender".

Nesse sentido, é possível identificar a tentativa de modificar o currículo a partir do Tema Gerador, proporcionando um outro olhar para um tema já trabalhado pelas escolas, mas, desta vez, contextualizado, refletindo e investigado, a partir do estudo da realidade. Em pesquisa desenvolvida por Giacomini e Muenchen (2016), os autores constataram que há maior interesse dos alunos ao trabalhar a partir de um tema relacionado à realidade vivenciada pelos alunos.

De acordo com Moreira, 2009

\begin{abstract}
$\mathrm{Na}$ escola, o currículo - espaço em que se concretiza o processo educativo pode ser visto como o instrumento central para a promoção da qualidade na educação. É por meio do currículo que as ações pedagógicas se desdobram nas escolas e nas salas de aula. É por meio do currículo que se busca alcançar as metas discutidas e definidas, coletivamente, para o trabalho pedagógico. O currículo corresponde, então, ao verdadeiro coração da escola. Daí a necessidade de permanentes discussões sobre o currículo, que nos permitam avançar na compreensão do processo curricular e das relações entre o conhecimento escolar, a sociedade, a cultura, a autoformarão individual e o momento histórico em que estamos situados (MOREIRA, 2009, p. 5).
\end{abstract}

Nesse sentido, a escola não irá resolver os problemas da sociedade, mas ela tem papel fundamental na transformação de uma sociedade mais justa e democrática. Essa transformação passa também pela forma como a escola concebe o currículo.

Dessa forma, na categoria: A reestruturação do currículo a partir do trabalho com os Temas Geradores, buscamos apresentar e refletir sobre a visão de currículo dos participantes da pesquisa, bem como sobre a ampliação dessa visão a partir do trabalho com Temas Geradores. 


\title{
CATEGORIA 2: O TRABALHO INTERDISCIPLINAR E COLETIVO
}

A ideia de trabalhar com grades curriculares que se organizam a partir de disciplinas que representam áreas do conhecimento é muito presente no cotidiano escolar e parece estar naturalizada (GALLO, 2009). Esta cultura da fragmentação é visível, até mesmo, nas estruturas das universidades que são organizadas e separadas em departamentos, os quais nem sempre se relacionam e trabalham de forma integrada. Para cursos de formação de professores, esta falta de articulação pode ser um empecilho, dificultando a relação entre teoria e prática, como pode ser visualizado abaixo:

Nem aqui no curso se faz um trabalho interdisciplinar. Existem algumas disciplinas que, às vezes, tentam. Daí depois nós somos cobrados a fazer (BOLSISTA F).

\begin{abstract}
Além dos supervisores, os bolsistas destacaram que, na graduação, se fala muito em interdisciplinaridade, mas na prática não enxergam isso. As disciplinas do curso não conversam. As vezes alguns professores fazem atividades integradas, como aquela da saída de campo para os Aparados, mas são poucas (DIARIO DA PESQUISADORA).
\end{abstract}

A interdisciplinaridade e o trabalho coletivo foram buscados em todos os momentos da investigação, sendo destacados como pontos positivos tanto pelos bolsistas da biologia, como pelos da química, bem como pelos supervisores. Foi possível ampliar o campo teórico e vivenciar, na prática, a importância de um trabalho interdisciplinar, principalmente a partir da etapa da Organização do Conhecimento.

Muenchen, ao sintetizar esta etapa, afirma que

[...] o estudo problematizado dos dados levantados sobre a comunidade apresenta situações significativas, que precisam ser organizadas e analisadas, situando-as no contexto da realidade, assim como ao nível macro social ou global. É esse trabalho que entusiasma um diálogo interdisciplinar, ou seja, - tema desafia as disciplinas a selecionar e integrar conhecimentos, permitindo assim uma leitura crítica da realidade (grifo meu) (MUENCHEN, 2010, p. 127).

É possível visualizar, no trecho abaixo, a importância desse diálogo interdisciplinar, que foi apresentado pelo bolsista, quando este destacou a relação entre a biologia e a química: "É bem mais produtivo, pois fica uma ligação, o assunto não termina, eu abordei polímeros, o pessoal da biologia abordou plástico. Daí eles abordaram a composteira e a química trabalhou os micronutrientes" (BOLSISTA A).

A ideia de que é possível esta integração entre as áreas, fez-se presente também nas ideias de outro bolsista: "A interdisciplinaridade, para alguns, é algo impossível, mas, na minha opinião, é possível. Exige um grande esforço por parte dos envolvidos, mas, através do diálogo, nós conseguimos fazer (DIÁRIO BOLSISTA L).

Ao pensar em um processo coletivo, pensa-se no envolvimento de todos alunos, professores, pais e comunidade - como sujeitos ativos na escolha do Tema Gerador. Essa participação da comunidade foi destacada pelos participantes. 
[...] porque parte deles. Porque a gente foi lá e fez a investigação e isso partiu deles. Então eu acho que eles realmente queriam falar sobre aquilo e eles tinham curiosidade sobre aquilo. Eu acho extremamente importante tu falar de algo que é do interesse do aluno, porque assim faz mais sentido para eles, na vida cotidiana deles, algo que está na vida cotidiana deles, porque no caso do tema drogas é algo do cotidiano dos alunos e cada vez mais. Por isso eu acho interessante falar sobre isso (BOLSISTA B).

Foi um desafio, trabalhar de forma interdisciplinar, mas possível. É muito importante, porque assim conseguimos relacionar os problemas do meio onde a escola está inserida, para depois buscar soluções (SUPERVISOR B).

Nas escolas parceiras do PIBID, a dificuldade do trabalho interdisciplinar e coletivo foi relacionada a falta de tempo, bem como a uma formação inicial e continuada que não possibilitou nem possibilita este tipo de discussão e ação. Em relação a questão do tempo, foi destacado que "Ainda temos o problema de tempo para planejar, apesar de já termos avançado um pouco, pois temos os encontros por área" (SUPERVISORA B); "Tem o problema que alguns professores trabalham em várias escolas, duas até três escolas diferentes e isso dificulta, não dá tempo para planejar" (SUPERVISORA C).

A questão é como possibilitar aos professores estes espaços de discussão, momentos de aperfeiçoamento, de qualificação, dentre outros, tendo em vista que a estrutura escolar é limitadora do trabalho do professor, que se restringe a dar aulas, preencher cadernos de chamada, participar de reuniões e resolver problemas sem refletir sobre eles. Isso vem ao encontro da ideia de proletarização dos professores, destacada por Contreras (2002), o qual salienta que essa proletarização impede a reflexão, isola os professores que, por falta de tempo disponível, não trabalham e não pensam coletivamente. Para o autor, os docentes, como categoria, "sofreram ou estão sofrendo uma transformação, tanto nas características de suas condições de trabalho como nas tarefas que realizam, que os aproxima cada vez mais das condições e interesses da classe operária" (CONTRERAS, 2002, p.33).

Em relação ao desenvolvimento do trabalho, as supervisoras destacaram que

Consegui ver um trabalho integrado e, além disso, outros professores trabalharam também. A professora de português, a de filosofia e a de história. As turmas dos terceiros anos, se organizaram e foram apresentar para o Ensino Fundamental!!! [...] Difícil do professor sair do seu conteúdo e trabalhar...mexer com uns professores que estão trabalhando e tu chega com um tema e eles precisam parar o conteúdo...complicado, eles não gostam. Mas desta vez, alguns professores assumiram o tema também. Foi muito bom (DIÁRIO SUPERVISORA C).

O pessoal das linguagens trabalhou em forma de texto, dos jornais da região, redação. Quer dizer que, além da área da natureza, outros trabalharam. Em PPDA os alunos apresentaram (SUPERVISORA A).

No relato da supervisora $C$, pode-se perceber que existe a ideia de que, quando trabalhado com tema, é necessário parar o conteúdo para desenvolvê-lo e, após, retornam-se os conteúdos. No entanto, o que se objetiva é uma mudança de postura em relação a essa concepção, ou seja, que a partir do tema sejam escolhidos os conhecimentos necessários para sua compreensão, conforme descrevem autores como (MUENCHEN, 2010; ARAÚJO, 2015). 
A importância do trabalho coletivo também ficou evidente na fala do bolsista como descrito abaixo.

Então eu acho que é interessante, assim como tu conseguir mostrar para os alunos que o conhecimento é muito aberto, que os conhecimentos de uma área podem ser aplicados em outras áreas também. É como eu digo sempre, a gente sabe, as vezes é o mesmo conteúdo, ensinado em duas disciplinas diferentes, como os elétrons e os prótons ensinados na química. Quando você aprende isso na física, você fica, você não entende, parecem duas coisas totalmente diferentes, e isso é uma falha, porque a gente deveria saber utilizar esses conhecimentos, saber que se referem a mesma coisa. Assim como também nas drogas, a gente não saberia falar da parte química, mas os bolsistas da química falaram e nós agregamos a parte biológica. Eu acho que os alunos conseguem ter uma maior dimensão do problema das drogas por vários aspectos, vão saber a origem das drogas, como são feitas as drogas, os conhecimentos químicos, vão saber também que as drogas, muitas vezes, são feitas dos produtos que se utiliza em casa, então ampliam os conhecimentos. Eu acho que é bem interessante trabalhar de forma interdisciplinar, que é outra coisa que os professores se confundem muito, e os alunos mesmos não sabem o que é interdisciplinaridade. Então eu acho que é interessante investir mais em interdisciplinaridade (BOLSISTA E).

O trabalho interdisciplinar e coletivo não aconteceu de forma fácil. Foram necessárias discussões e reflexões sobre o tema, bem como tempo para que os planejamentos interdisciplinares acontecessem. Esse desafio já foi afirmado em outros trabalhos no âmbito do grupo GEPECiD, como o Centa (2015) e Araújo (2015), quando desenvolveram suas pesquisas em escolas de Santa Maria. No entanto, apesar das dificuldades, a interdisciplinaridade é defendida como

[...] um progresso em relação ao ensino tradicional, com princípio na reflexão crítica sobre a própria estrutura do conhecimento, com o objetivo de superar a separação entre as disciplinas e refletir o papel dos educadores na formação dos educandos para o contexto atual em que estamos inseridos (CENTA, 2015, p. 21)

Também cabe enfatizar que a participação no PIBID auxiliou e encorajou o desenvolvimento do trabalho, pois a troca de experiências e as discussões, proporcionadas desde o processo formativo, possibilitaram vislumbrar que é possível a implementação de planejamentos interdisciplinares, tornando, tanto a biologia quanto a química, áreas atraentes para os alunos.

Dessa forma, na categoria: o trabalho interdisciplinar $e$ o coletivo apresentamos a importância da interdisciplinaridade e do trabalho coletivo no processo educativo. Foi possível reconhecer a necessidade de mudança de visão, tanto nos cursos de formação inicial como na formação continuada, em relação a interdisciplinaridade. Faz-se necessária uma formação que, além de discussões teóricas, proporcione vivências de práticas interdisciplinares.

\section{CATEGORIA 3: O DIÁLOGO COMO FORMA DE POSSIBILITAR A PROBLEMATIZAÇÃO DA REALIDADE}

Nesta categoria, discutem-se dados a partir de ideias de Freire (2014) como o realidade, a fim de modificá-la a partir do diálogo. 
$\mathrm{Na}$ dialogicidade, a problematização, educador-educando e educando educador vão ambos desenvolvendo uma postura crítica da qual resulta a percepção de que este conjunto de saber se encontra em interação. Saber que reflete o mundo e os homens, no mundo e com ele, explicando o mundo, mas sobretudo, tendo de justificar-se na sua transformação (FREIRE, 1977, p. 55).

O diálogo emergiu, durante o processo de análise, como forma de possibilitar a problematização da realidade vivida pelo educando e foi destacado pelos sujeitos participantes como primordial no processo de problematização, possibilitando o pensar, refletir e agir a partir da realidade vivenciada.

O diálogo proporcionado pelo Tema Gerador, desde sua busca até sua implementação, como vem sendo discutido, foi importante por contribuir na ampliação do pensamento dos professores supervisores e dos bolsistas, no sentido de reconhecerem que, a partir das trocas, do ouvir os outros, aprendo, construo e reconstruo minha prática como profissional e pessoa.

Eu acho que, para nós, pelo menos, eles participaram sempre de todas as aulas, e eu acho que, porque eles estavam envolvidos naquilo, eles tinham noção do que eles estavam vendo. Eles sabiam que aquilo que a gente estava falando era a realidade que eles se encontravam. E, a partir daí eles queriam participar para ver o que poderiam fazer para melhorar a realidade. E eu acho também que eles gostaram bastante do jeito que a gente trabalhou, que foi uma coisa que eles sugeriram (BOLSISTA C).

Eu acho importante porque eu tenho a possibilidade de trabalhar um tema que os meus alunos tenham interesse. E a partir disso fazer ligação com o cotidiano deles, assim eles participam do diálogo, se posicionam, trocam ideias (BOLSISTA B).

Conforme Freire (2014), o diálogo é ponto de partida para que sejam pensados os conteúdos a serem trabalhados pelo professor, quando se busca uma educação problematizadora e libertadora.

\section{De acordo com Halmenschlager}

A interlocução entre os docentes, na perspectiva de um trabalho coletivo na elaboração e implementação de práticas inovadoras, precisa ser garantida para o que o diálogo aconteça entre os pares. Sob esse ponto de vista, o diálogo constitui o eixo norteador para a construção das propostas de ensino e não somente em sala de aula, como estratégia de ensino (grifo meu) (HALMENSCHLAGER, 2014, p. 191).

A aproximação com o cotidiano, a partir do Estudo da Realidade, foi problematizada e discutida pelos grupos nos planejamentos e o diálogo esteve presente durante todas as etapas do processo, como exemplificado no planejamento de um dos grupos, a partir do documentário intitulado llha das Flores $^{1}$.

O que acharam? Era o que vocês esperavam? Sobre o que fala o documentário? Como enxergamos as pessoas que vivem na ilha das flores? Elas são vistas da mesma forma que um produtor rural, médico, professor? Por quê? Por que o documentário insiste em falar que os seres humanos são mamíferos que se distinguem dos demais por serem dotados de telencéfalo altamente desenvolvido e polegar opositor? A partir do que você viu, você acha que somos inteligentes? O que é ser inteligente? No final do filme é dada o conceito de liberdade. O que é ser livre para você? Os seres humanos 
apresentados no filme são livres? Por quê? 0 documentário mostra o problema do lixo. Aqui em São Vicente existe este problema também? Você sabe para onde vai o lixo produzido na sua casa? E o lixo de todo município vai para onde? O que é lixo para você? (grifo meu) (PLANEJAMENTO DO GRUPO).

Esses momentos de estímulo aos alunos, a fim de que eles expusessem seus conhecimentos e sentissem-se à vontade em fazê-lo foram fundamentais para o sucesso do projeto. Esta ideia vem ao encontro da afirmação de Freire,

Estimular a pergunta, a reflexão crítica sobre a própria pergunta, o que se pretende com esta ou aquela pergunta em lugar da passividade em face das explicações discursivas do professor, espécie de respostas a perguntas que não foram feitas. Isso não significa realmente que devamos reduzir a atividade docente em nome da defesa da curiosidade necessária, o puro vai e vem de perguntas e respostas, que burocraticamente se esterilizam. A dialogicidade não nega a validade de momentos explicativos, narrativos em que o professor expõe ou fala do objeto. O fundamental é que o professor e alunos saibam que a postura deles, professor e alunos, é dialógica, aberta, curiosa, indagadora e não apassivada, enquanto fala ou enquanto ouve. 0 que importa é que professor e alunos se assumam epistemologicamente curiosos (FREIRE, 2014, p. 83).

Para Pernambuco (1993), o diálogo sobre um assunto, sobre concepções de mundo, é o que mobiliza e mantém o grupo em movimento.

Dialogar significa navegar pelo mar das semelhanças suficientes para que se possa estabelecer uma comunicação e das diferenças suficientes para não estarmos repetindo uns aos outros, em um diálogo que vira monólogo (PERNAMBUCO, 1993, p. 24).

Através do diálogo e do trabalho coletivo, foi possível desenvolver uma prática educativa participativa, na qual os problemas da comunidade foram evidenciados e problematizados pelos grupos a partir dos planejamentos. $\mathrm{O}$ trabalho com base nesses problemas aproxima a escola da comunidade, tornando-as parceiras no trabalho educativo.

Esta interação entre escola e comunidade foi importante para que se fortalecessem os laços de pertencimento entre ambas. Este aspecto foi apontado pelos bolsistas, quando questionados sobre a importância do trabalho.

A gente passa a ver a concepção de diversos tipos de pessoa, porque a gente não aplicou somente para os discentes, a gente aplicou para diversos setores. Então, eu acho que você vê que as pessoas são tão diferentes, mas, na verdade, são tão parecidas, sabe. A realidade delas é totalmente diferente, em alguns os aspectos, mas os problemas são os mesmos (BOLSISTA E).

Gostei muito do tema. Fiquei feliz com o tema escolhido. Trabalhar sobre drogas é sempre interessante. Percebi como os alunos precisam discutir e conhecer este assunto. Foi legal porque foi escolhido pelos alunos, pais e comunidade. Se a gente levasse o tema não seria legal. Gerou curiosidade dos alunos e teve a participação e o envolvimento deles (BOLSISTA I).

Na entrevista, esta supervisora também destacou a ida até a comunidade. 
casas. Acho que isso foi bem importante. Até porque a gente achava que seria um tema e foi outro. Por uma coisa é meu ponto de vista o do outro é outra (SUPERVISORA B).

Nesse sentido, o trabalho possibilitou vivenciar, a partir do diálogo realizado no decorrer do ER, os problemas da comunidade, através das falas das pessoas e da visualização das ruas, das casas, dentre outras, indo ao encontro do que Freire (2014) defendia.

Na categoria o diálogo como forma de possibilitar a problematização da realidade, buscamos destacar a importância de uma prática educativa dialógica e que problematize a realidade vivenciada pelos sujeitos, no sentido de possibilitar a reflexão sobre os problemas dessa realidade, bem como pensar coletivamente algumas possibilidades de buscar alternativas para melhorar.

\title{
CATEGORIA 4: UM NOVO OLHAR PARA A ESCOLA E PARA A INSTITUIÇÃO DE ENSINO SUPERIOR
}

No presente trabalho, teve-se o intuito de possibilitar reflexões, em conjunto com os professores da Educação Básica, e encontrar alternativas de superação dos problemas vivenciados. Essa ideia, fica evidente nessa categoria, pois a partir das falas e relatos é possível reconhecer a importância em ampliar a relação entre escolas e Instituições de Ensino Superior. Mesmo que, na proposta apresentada pela pesquisadora, já se tivesse esta visão mais ampla do papel da escola, o desenvolvimento do projeto fortificou concepções em relação à importância do trabalho participativo, dialógico e coletivo.

\begin{abstract}
Foi algo sempre discutido, debatido. Porque a nossa formação sempre vem alguém que fala, já sabe o que vai falar e no final abre para perguntas a gente está louco $p$ ir embora. Esse não, desde o momento que a gente chegou, você tinha que estar por dentro do assunto, ler, participar. A gente foi ouvida e falou, deu nossas ideias e falou sobre o que a gente faz na escola, o que dá certo e o que não (SUPERVISORA B).
\end{abstract}

Dessa forma, buscou-se romper com a cultura da escola básica como espaço de depósitos. Reconhecem-se avanços, inclusive na visão que os professores da Educação Básica têm deles próprios, como aparece através das falas durante a entrevista com os supervisores.

\begin{abstract}
Eu acho que cada leitura, cada dia que a gente chegava lá era algo novo, porque foi bem amplo, bem criativo. As vezes a gente chegava lá e ficava pensando será que eu vou saber, vou saber responder as perguntas, vou saber explicar o que entendi. Às vezes me sentia até apreensiva pensando se ia falar correto. Os alunos do PIBID estudam, tem bastante leitura, a gente não tem tanto como eles (SUPERVISORA B).
\end{abstract}

No entanto, com o passar do tempo, devido ao estímulo à participação e à cooperação, foi modificando a postura da supervisora, de maneira que ela foi superando a visão de que não teria como contribuir e de que os outros sabiam mais por estarem na formação inicial.

Autores como Nóvoa (1992), Imbernón (2016), Sauerwien (2008) defendem que a formação dos professores não é construída a partir de cursos que são acumulados ao longo da carreira, mas por um trabalho de reflexão sobre a sua 
própria prática, construindo e reconstruindo seu trabalho, a partir das suas vivências e experiências.

Os outros cursos te colocam em forma de uma palestra. Eles te jogam teoria e tu que se vire na prática, se tu conseguires aliar é problema teu. Não tem ninguém te ajudando, discutindo e fazendo contigo (SUPERVISORA C).

Através desta fala, é possível reconhecer o descontentamento com os cursos de formação que vêm sendo proporcionados para a escola e a falta de apoio e de discussão sobre os assuntos relacionados à realidade desse contexto.

Em relação à mudança de visão do papel da instituição de Ensino Superior, os supervisores relataram que nem sempre estão esperando ideias prontas, pois sentem necessidade de participar. Esta necessidade também foi evidenciada, quando se demonstraram participantes no curso de forma efetiva, falando, apresentando ideias, realizando o processo de investigação e de implementação dos planejamentos, que os fez se sentirem sujeitos ativos que podem contribuir.

Por outro lado, torna-se importante destacar que os resultados deste trabalho foram possibilitados pelo espaço proporcionados pelo PIBID, como se pode visualizar nas falas:

\begin{abstract}
A diferença é que o PIBID nos proporciona conhecimentos da Educação como um todo, partindo de pressupostos teóricos, o que, em minha opinião, é de grande importância, entendendo e estudando estas teorias para, então, serem aplicadas a partir disso, em outras ações específicas, podendo ser usadas em todas as áreas, com atividades diferenciadas, com os alunos, em sala de aula. Enquanto outros processos formativos do qual participei foram bons também, acrescentaram na minha formação, com certeza, até porque todo e qualquer curso ligado ao nosso trabalho é válido, conhecimento é sempre somatório, porém, os assuntos tratados eram isolados, de forma mais resumida (SUPERVISORA D).
\end{abstract}

Isso é uma coisa boa, porque você pensa que quando tu és novo te da aquele friozinho e eu com 23 anos de magistério sinto isso, não se tornou aquela coisa, rotina, tanto faz como tanto fez. Então isso é uma coisa boa, essa troca com eles mantém a motivação e faz a gente se sentir importante (SUPERVISORA A).

Nesse sentido, o PIBID novamente aparece como possibilidade de construção de conhecimentos e de troca de experiências entre escola de Educação Básica e instituição de Ensino Superior.

A articulação entre o PIBID e a escola de Educação Básica proporcionou uma ampliação da visão dos bolsistas também, fazendo com que estes reconhecessem que é importante a troca e não o "levar" atividades pensadas por eles para as escolas. Terneiro e Goes (2015) relatam que os cursos que formam professores das instituições de ES, a partir do PIBID, passam a ter uma relação mais estreita com as escolas. Essa relação tem um caráter importante, no que diz respeito ao diálogo, à reflexão e à articulação.

Por fim, nessa categoria: um novo olhar para a escola e para a instituição de ensino superior, apresentamos a visão de que a escola de educação básica pode ser um lugar onde se constrói conhecimentos em relação à docência. A partir do trabalho que foi desenvolvido no âmbito do PIBID defende-se a uma parceria entre a escola e as IES na formação de professores que legitime os docentes como 
sujeitos autônomos, pensadores e elaboradores de currículos, bem como, capazes de pensarem sobre sua própria formação.

\section{CONSIDERAÇÕES FINAIS}

É possível reconhecer, a partir do trabalho desenvolvido, a importância em pensar currículos de ciências voltados à problematização da realidade e interdisciplinar. Considera-se que os professores, como sujeitos reflexivos, de forma compartilhada, elaborem os currículos das escolas, possibilitando aos sujeitos terem voz com vistas às mudanças da realidade.

Em relação a essa ideia, o PIBID proporcionou, a partir do processo formativo, a busca pelos Temas Geradores e as implementações nas escolas, assim como a visão de que é possível realizar um trabalho compartilhado. Nesse sentido, o espaço do PIBID pode, além de pensar e implementar metodologias, auxiliar na reflexão e na elaboração de currículos críticos transformadores.

Além disso, discussões curriculares são fundamentais na formação inicial e na permanente, no sentido de colocar o professor como sujeito que pode pensar e elaborar currículos de forma dialógica, contextualizada e interdisciplinar. No entanto, desenvolver propostas curriculares interdisciplinares não é um processo simples. Além de uma estrutura escolar que possibilite o trabalho, é imprescindível que, já nos cursos de formação docente, se proporcione aos licenciandos, além de discussões e reflexões sobre o tema, vivências nos espaços da instituição e da escola de Educação Básica.

Os professores supervisores e os bolsistas do PIBID consideraram, ao final do trabalho desenvolvido, que o processo formativo vivenciado por eles foi diferenciado no sentido de possibilitar a troca de ideias e construção de aprendizagens de forma compartilhada, ou seja, visou-se criar um espaço onde todos podem falar e todos têm ideias e experiências a compartilhar. Assim, apesar das dificuldades, o trabalho desenvolvido promoveu o compartilhamento de ideias e a construção de um currículo coletivo, fortificando a necessidade de repensar e implementar currículos que possibilitem a participação dos professores, bem como da comunidade escolar. 


\title{
DEVELOPMENT AND IMPLEMENTATION OF CRITICAL CURRICULUM/TRANSFORMERS: A LOOK AT A TRAINING PROCESS WITHIN THE SCOPE OF PIBID
}

\begin{abstract}
This study presents the results obtained from a training process developed with fellows and supervisors of the Institutional Program for Teaching Initiation Scholarships (PIBID) in order to reflect on the possibility of implementing critical / transforming curricula in science education. The results obtained from a questionnaire, interviews and diaries prepared by the subjects participating in the research were analyzed in the light of the Discursive Textual Analysis (ATD) and four emerging categories were arrived at: The restructuring of the curriculum based on working with the Generating Themes; Interdisciplinary and collective work; Dialogue as a way of enabling the problematization of reality; and A new look at the school and the Higher Education institution. From the categories, it was possible to recognize the importance of initial and continuing education in the development of critical curricula, as well as the need for collective and interdisciplinary work in science education.
\end{abstract}

KEYWORDS: Curriculum. Generating Themes. PIBID. 


\section{NOTAS}

1 Documentário brasileiro de 1989, dirigido por Jorge Furtado que apresenta a trajetória de um tomate, desde a colheita ao descarte por uma dona de casa, até a chegada ao lixão da ilha, onde crianças disputam alimentos que sequer servia de alimento para os porcos.

\section{REFERÊNCIAS}

ARAUJO, L. B. Os três Momentos pedagógicos como estruturantes de Currículo. 2015. 2015. 150 p. Dissertação (Mestrado em Educação em Ciências) Universidade Federal de Santa Maria, Santa Maria, RS, 2015.

AULER, D. Enfoque Ciências-Tecnologia-Sociedade: Pressupostos para o Contexto Brasileiro. Ciência \& Ensino, v. 1, número especial. 2007. p. 1 - 20.

CENTA, F. G. Avanços e desafios alcançados por professores de Ciências de uma escola pública de Santa Maria/RS na estruturação e implementação do tema "Arroio Cadena: cartão postal de Santa Maria".203. Dissertação (Mestrado em Educação Matemática e Ensino de Física) - Universidade Federal de Santa Maria, Santa Maria, RS, 2015.

DELIZOICOV, D.; Conhecimento, Tensões e Transições. Tese. São Paulo: FEUSP, 1991.

DELIZOICOV, D.; ANGOTTI, J. A.; PERNAMBUCO, M. M. Ensino de Ciências: fundamentos e métodos. 4. ed. São Paulo: Cortez, 2011.

DEMARTINI, G. R.; SILVA, A. F. G. Abordagem Temática na sistematização curricular para o ensino de ciências: gravidez na adolescência em uma escola estadual do município de Sorocaba-SP. Atas do IX Encontro Nacional de Pesquisa em Educação em Ciências (ENPEC). Águas de Lindóia, 2013.

FERREIRA, M. V.; PANIZ, C. M.; MUENCHEN, C. Os três momentos pedagógicos em consonância com a abordagem temática ou conceitual: uma reflexão a partir das pesquisas com olhar para o ensino de ciências da natureza. Ciência e Natura, v.38, n.1, p. 513-525, jan./abr., 2016.

FREIRE, P. Pedagogia do Oprimido. Rio de Janeiro: Paz e Terra, 2014.

GALLO, S. Currículo: entre disciplinaridades, interdisciplinaridades... e outras ideias! Salto para o Futuro. Ano XIX - № 1 - abril/2009. 
HALMENSCHLAGER, K. Abordagem de temas em Ciências da Natureza no Ensino Médio: implicações na prática e na formação docente. 2014. 373 p. Tese (Doutorado em Educação Científica e Tecnológica) - Universidade Federal de Florianópolis, Florianópolis, 2014.

IMBERNÓN, F. Qualidade do Ensino e Formação do Professorado: uma mudança necessária. São Paulo: Cortez, 2016.

KRASILCHIK, M. Caminhos do ensino de Ciências no Brasil. Em Aberto, Brasília, ano 11, no.55, jul/set. 1992, p. 3-8.

LOPES, N. C.; CARVALHO, W, L, P. A Constituição de Associações Livres para o Trabalho com as Questões Sociocientíficas na Formação de Professores. Revista de Ensino de Ciências e Matemática, v. 9, n.3, 2018, p. 1-20

MUENCHEN, C. A Disseminação dos Três Momentos Pedagógicos: um estudo sobre as práticas docentes na região de Santa Maria/RS. Florianópolis: Tese de Doutorado, Universidade Federal de Santa Catarina, 2010.

MOREIRA, A. F. B. Antônio Flavio Barbosa Moreira: pesquisador em currículo. Belo Horizonte: Autêntica, 2010.

NÓVOA, A. Formação de Professores e Profissão Docente. In: NÓVOA, A (org). Os professores e sua formação. Lisboa: Dom Quixote, 1992.

MORAES, R.; GALIAZZI, M. C. Análise Textual Discursiva: processo reconstrutivo de múltiplas faces. Ciência e Educação, v. 12, n. 1, 2006, p. 117- 128.

MORAES, R. Uma tempestade de luz: a compreensão possibilitada pela análise textual discursiva. Ciência \& Educação, v.9, n. 2, 2003, p. 191-211

PANIZ, C. M. O PIBID como política articuladora na construção de currículos críticos: o trabalho desenvolvido no Instituto Federal Farroupilha - Campus São Vicente do Sul. Tese (Doutorado em Educação em Ciências). Santa Maria: UFSM, 2017.

SACRISTÁN, G. (org). Saberes e Incertezas sobre o currículo. Porto Alegre: Penso, 2013.

SANTOS, R. A. et al. Repensar a educação em ciências: repensar o currículo. In: 
SAUERWEIN, I. P. S. A Formação Continuada de Professores de Física - natureza, desafios e perspectivas. 239. Tese (Doutorado em Educação Científica e Tecnológica) - Universidade Federal de Santa Catarina, Florianópolis, Santa Catarina, SC, 2008.

TERNEIRO, M. O. V.; GÓES, G. T. (Org). Universidade e Educação Básica: parceria necessária na formação de professores. Ponta Grossa: Editora UEPG, 2015.

TOMAZETTI, E. M.; BENETTI, C. C. Formação do professor de Filosofia: entre o ensino e a aprendizagem. Revista Diálogo Educ. Curitiba, v.12, n.37, p. 1027- 1043, 2012.

Recebido: 17 ago. 2019

Aprovado: 13 jan. 2020

DOI: $10.3895 /$ rbect.v13n3.10550

Como citar: PANIZ, C. M.; MUENCHEN, C. Elaboração e implementação de currículos

críticos/transformadores: um olhar para um processo formativo no âmbito do PIBID. Revista Brasileira de

Ensino de Ciência e Tecnologia, Ponta Grossa, v.13, n. 3, p. 224-242, set./dez. 2020. Disponível em:

<https://periodicos.utfpr.edu.br/rbect/article/view/10550>. Acesso em: XXX.

Correspondência: Catiane Mazocco Paniz - catiane.paniz@iffarroupilha.edu.br

Direito autoral: Este artigo está licenciado sob os termos da Licença Creative Commons-Atribuição 4.0 Internacional. 